\title{
BEHAVIOR OF BEARING PLATES RESTING ON DIFFERENT TYPES OF SANDY SOIL
}

\author{
Mohamed Saad Eldin Mohamed \\ Soil Mechanics and Foundations, Department of Civil Engineering, AL-Azhar \\ University.Cairo,Egypt \\ E-mail: e_msaad@yahoo.com
}

\begin{abstract}
This Study focuses on carrying out a numerical analysis to simulate the behavior of square thick and thin plates rested on sand soils with different densities using PLAXIS 3D program. The selected soil density categories in this work are as following: loose, med dense and dense. This enables to investigate the impact of soil type and density in addition to the plate thickness on the behavior of the plate where the settlements and moments are estimated for various stresses applied on the plate. The plate thickness are $0.5 \mathrm{~m}$ and $1.30 \mathrm{~m}$ for thin and thick plates respectively. The dimensions of the studied plate are $10.0 \mathrm{~m} \times 10.0 \mathrm{~m}$ while the area of finite element model of soil is represented by $100.0 \mathrm{~m} \times 100.0 \mathrm{~m}$ with depth $30.0 \mathrm{~m}$. Based on the obtained results, it can be observed that for plates resting on sand soil, thin plate has less settlements and moments for the three type of sand soil compared with those in thick one. This work provides a quantitative analysis for the plate behavior resting on different types of sand soil and it could be useful for geotechnical engineers to design safe and economic constructions.
\end{abstract}

\section{KEYWORDS : Plates, Thick Plate, Thin Plate, Cohesionless Soil, Loose Sand, Medium} Dense Sand, Dense Sand, Settlement.

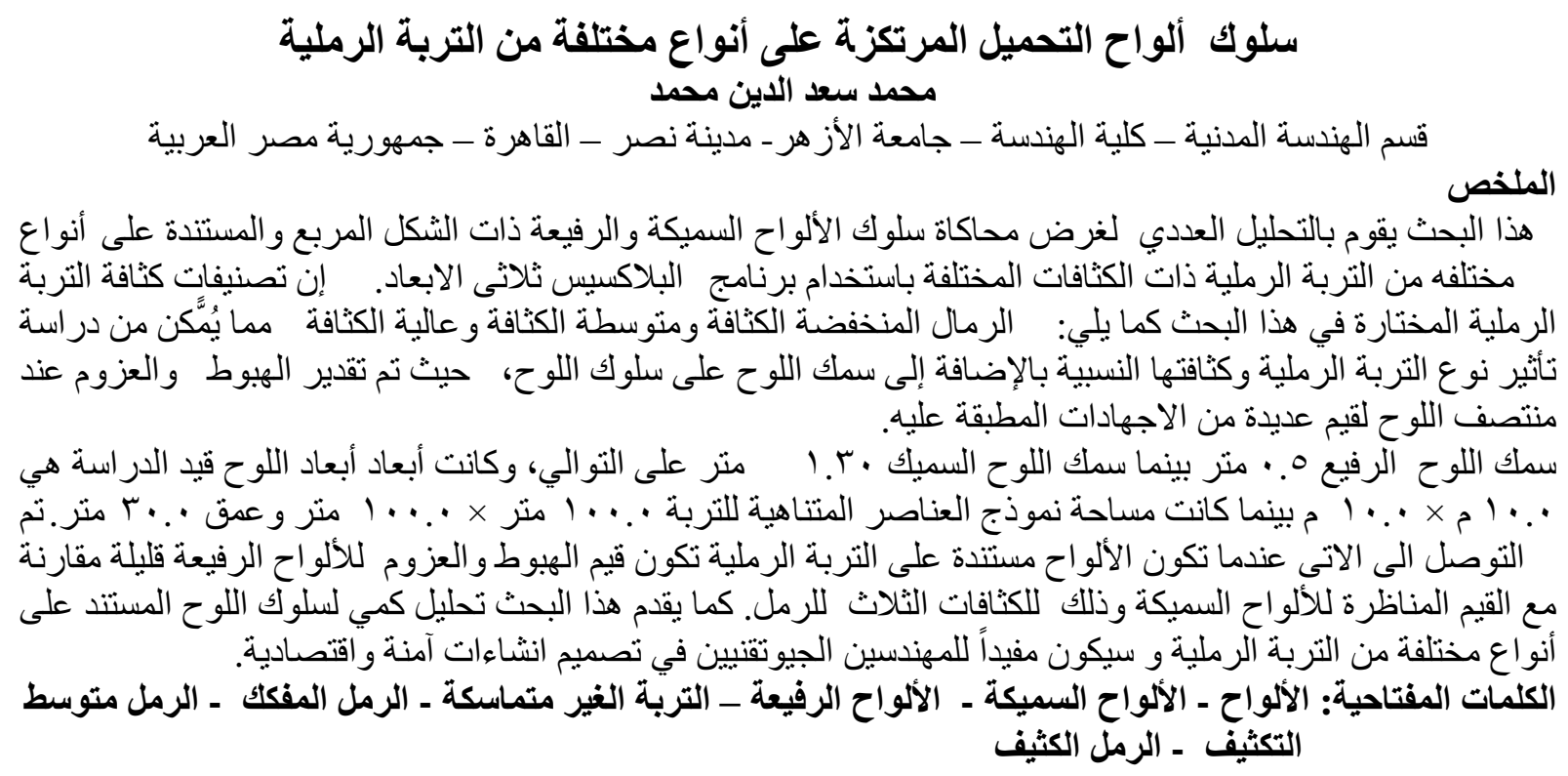

Plates resting on elastic foundation are encountered in many structural forms in aircrafts, bridges, footings of structures, and even slabs of buildings. In the design of plates rested on 
soil, the soil can be treated as a series of individual springs which know as Winkler model. The Winkler model treats soil as series of springs. It assumes that the pressure at any point on the surface of the soil is related to the modulus of subgrade reaction, which is known as the Winkler spring stiffness and the deflection of the soil. The spring stiffness depends on the settlement characteristic of the soil and the geometry of the foundation .This model can be easily handled by mathematical equations and can produce reasonably accurate results. However, it neglects the interaction between each individual spring and the supporting soil that is not modeled as continuum. As alternative approach that treats the supporting soil as an elastic continuum can better represent the physical behavior of the supported soil .The soil parameters used in this approach depend on the field stress state. In the literature, most studies in the analysis of plates focused on continuous plates resting on elastic springs according to Winkler model.

Therefore, the aim of this study is to demonstrate the behavior of plates resting on soil using PLAXIS 3D. Plates can be classified into three groups :

i) According to the ratio $(\mathrm{a} / \mathrm{h})$ where $\mathrm{a}=$ the shortest dimension of plate in plane and $\mathrm{h}=$ plate thickness.

\begin{tabular}{|c|c|}
\hline $\mathbf{a} / \mathbf{h}$ & Type of plates \\
\hline$\leq(8-10$ & The First group (thick plates) \\
\hline$\geq(80-100)$ & The Second group \\
\hline$(8-10) \leq \mathrm{a} / \mathrm{h} \leq(80-100)$ & The Third (thin plates) \\
\hline
\end{tabular}

ii) Depending on the value of the ratio $(\mathrm{w} / \mathrm{h})$ which the ratio of the maximum deflection of the plate to its thickness

\begin{tabular}{|c|c|}
\hline w/h & Type of plates \\
\hline$\leq 0.2$ & Stiff plates \\
\hline$\geq 0.3$ & Flexible plates \\
\hline
\end{tabular}

iii) According to materials:

Isotropic: all planes are symmetric in terms of elastic modulus and Poisson's ratio.

Orthotropic: there are three perpendicular symmetric planes.

Anisotropic: there are no symmetric planes.

Plates of isotropic materials have important application due to high bending stiffness.

\section{FNITE ELEMENT MODELING}

Finite element analyses were performed using the software PLAXIS 3D FOUNDATION. The elasto-plastic finite element analysis has been done by the 15-node wedge element in threedimensional PLAXIS program as shown in Figure (1).The 15-node wedge element is composed of 6-node triangles in horizontal direction and 8-node quadrilaterals in vertical direction. The accuracy of the 15-node wedge element and the compatible structural elements are comparable with the 6-node triangular element and compatibles in a 2D PLAXIS analysis. Due to the presence of non-horizontal soil layers, some 15-node wedge elements may degenerate to 13-node pyramid elements or even to 10-node tetrahedral elements.

The discretion of both soil and pile has been done using the automatically mesh generation method in PLAXIS program with local refinement. The local refinement is used in areas where large stress concentrations or large deformation gradients are expected and it is desirable to 
have a more accurate finite element mesh whereas other parts of the geometry might not require a fine mesh in order to reduce the computational efforts.

To avoid boundary effects, the finite element model of soil which are loose sand, medium dense sand and dense sand soils is represented by area $100.0 \mathrm{~m} \mathrm{x} 100.0 \mathrm{~m}$ with $30 \mathrm{~m}$ depth while The dimensions of the studied plate are $10.0 \mathrm{~m} \times 10.0 \mathrm{~m}$ and the plate thickness are $0.5 \mathrm{~m}$ and $1.30 \mathrm{~m}$ for thin and thick plates respectively as shown in Figure (2).

The plate thickness are $0.5 \mathrm{~m}$ and $1.30 \mathrm{~m}$ for thin and thick plates respectively. The dimensions of the studied plate are $10.0 \mathrm{~m} \times 10.0 \mathrm{~m}$ while the area of finite element model of soil is represented by $100.0 \mathrm{~m} \times 100.0 \mathrm{~m}$ with depth $30.0 \mathrm{~m}$.

The materials properties for plate and soil are given as as following:

\begin{tabular}{|c|c|c|c|c|c|}
\hline \multirow[t]{2}{*}{ Material } & \multicolumn{5}{|c|}{ Properties } \\
\hline & $\begin{array}{c}\text { Dry unit weight } \\
{\left[\gamma_{\mathrm{d}}\right]} \\
\mathrm{kN} / \mathrm{m}^{3}\end{array}$ & $\begin{array}{c}\begin{array}{c}\text { Relative } \\
\text { density }\end{array} \\
{\left[D_{\mathrm{r}}\right]}\end{array}$ & $\begin{array}{c}\text { Modulus of } \\
\text { elasticity [ E ] } \\
k N / \mathrm{m}^{2}\end{array}$ & $\begin{array}{c}\text { Poisson's } \\
\text { ratio } \\
{[v]}\end{array}$ & $\begin{array}{c}\text { Angle of } \\
\text { internal } \\
\text { friction }[\Phi]\end{array}$ \\
\hline Plates & 25.00 & & $2 \times 10^{6}$ & 0.20 & - \\
\hline Loose sand & 16.00 & $30 \%$ & 10000 & 0.30 & 30 \\
\hline $\begin{array}{c}\text { Medium } \\
\text { dense sand }\end{array}$ & 17.00 & $60 \%$ & 30000 & 0.35 & 35 \\
\hline Dense sand & 18.00 & $80 \%$ & 50000 & 0.40 & 40 \\
\hline
\end{tabular}

\section{Results and discussion}

This section will present the results of settlement and moment for thin and thick plates resting on different types of sand soils.

\subsection{Behavior of thin plate}

The thin plate is made up of reinforced concrete with thickness of $0.5 \mathrm{~m}$ and the different applied stresses are $\left(25,0 \cdot 1 \cdots, 1 \mathrm{r} 0,10 \cdot, 1 \vee 0 \mathrm{kN} / \mathrm{m}^{2}\right.$ and $\left.200 \mathrm{kN} / \mathrm{m}^{2}\right)$.

The analysis has been carried out and the settlement of soil and moment in thin plate are obtained. For example, Figures ( 3,4 and 5) present contours of settlement and values of settlement in thin plate and Figures.(6,7 and 8) present contours of moment in thin plate resting on loose, med and dense sand due to applied stresses.

To study the effect type of soil on the behavior of thin plate, the results obtained by the nonlinear analysis are analyzed. For simplicity, the results are presented by charts as follows: Figure (9) presents the effect of types of sand soil on the performance of the settlement of thin plate. Figure (9) illustrates the relationship between settlements and stresses of thin plate for different densities of sand soil. It is obvious that for different densities of soil, there is an increase in the settlement of soil with the increment of the applied stresses.

Figure (11) presents the comparison between settlement of thin plate resting on different types of sand soil. Figure (11) explains that settlement in loose sand soil is more than five times of 
that in dense sand soil and three times of that in med dense sand. The med dense sand soil has roughly as twice as the settlements values of those in dense sand soil.

The densities of soil have significant effect on the settlement of the sand soil on which the thin plate is rested.

Figure (10) illustrates the relationship between the moment and stress of thin plate resting on different densities of sand soil. It is obvious that for all soil densities, there is an increase in the moment on soil with the increment of the applied stresses.

Figure (12) indicates that the comparison between moments of thin plate resting on different densities of sand soil for different stresses. It is clear that the moment in thin plate have the biggest values while where it have the lowest values in the case of dense sand. There is no significant difference between the moment of med dense and dense sand soil. However, the moment of the loose sand soil is around twice of that in med dense and dense sand soil.

The above reported relationships indicate that med dense and dense sand soils are both suitable to be used in the model. When the implementation cost is a concern, the med dense sand soil can be used with acceptable quality.

\subsection{Behavior of thick plate}

The thick plate is made up of reinforced concrete with thickness of $1.3 \mathrm{~m}$ and the different applied stresses are $\left(25,0 ., 1 \cdots, 1 \mathrm{r} 0,10 \cdot, 1 \vee 0 \mathrm{kN} / \mathrm{m}^{2}\right.$ and $\left.200 \mathrm{kN} / \mathrm{m}^{2}\right)$.

The analysis has been carried out and the settlement of soil and moment in thin plate are obtained. For example, Figures (13,14 and 15) present contours of settlement and values of settlement in thick plate and Figures.(16,17 and 18) present contours of moment in thick plate resting on loose, med and dense sand due to applied stresses.

To study the effect type of soil on the behavior of thick plate, the results obtained by the nonlinear analysis are analyzed. For simplicity, the results are presented by charts as follows:

Figure (19) presents the effect of types of sand soil on the performance of the settlement of thick plate. Figure (19) illustrates the relationship between settlements and stresses of thick plate for different densities of sand soil. It is obvious that for different densities of soil, there is an increase in the settlement of soil with the increment of the applied stresses.

Figure (21) presents the comparison between settlement of thick plate resting on different types of sand soil. Figure (21) explains that settlement in loose sand soil is six times of that in dense sand soil and three times of that in med dense sand. The med dense sand soil has roughly as twice as the settlements values of those in dense sand soil.

The densities of soil have significant effect on the settlement of the sand soil on which the thin plate is rested.

Figure (20) illustrates the relationship between the moment and stress of thick plate restring on different densities of sand soil. It is obvious that for all soil densities, there is an increase in the moment on soil with the increment of the applied stresses.

Figure (22) indicates that the comparison between moments of thick plate resting on different densities of sand soil for different stresses. It is clear that the moment in thick plate in the case of loose sand almost is closed to med dense sand and dense sand. In other words, there is a little variation between the three values.

The above reported relationships indicate that dense and med dense sand soils are both suitable to be used in the model. When the implementation cost is a concern, the medium dense sand soil can be used with acceptable quality.

\subsection{Comparison between thick thin plates}

Figures $(23,24,25)$ represent the comparison between settlement of thin and thick plates rested on loose and med and dense sand soil for different stresses. It is obvious that the settlement of thick plate rested on different types of sand soil is slightly different from that in thin one while the thickness of the thick plate is around three times of the thin one.

The reported results indicate that the thin plate can be a perfect choice in implementing the model and this helps on reducing the implementation costs compared with the use of thick plate.

The results indicate that the thickness of the plate has very little effect on the settlement of the plate is rested on different types of sand soil. 
Figures $(26,27,28)$ represents the comparison between moment of thin and thick plate resting on loose, med and dense sand soil for different stresses. It is obvious that the moment of thick plate rested on different types of sand soil is considerably larger than that of thin plate. More specifically, the moment of the thick plate is around six times of the thin one.

This indicates that the thin plate can be a perfect choice in implementing the model to reduce the moment and the implementation costs. The results indicate that the thickness of the plate has major effect on the moment of the loose sand soil on which the plate is rested.

\section{CONCULSIONS}

This work demonstrated the behavior of thin and thick plates resting on sand soil with various densities using the finite element PLAXIS 3D foundation program. More specifically, the study quantitatively evaluated via PLAXIS simulation package the impact of the thickness of plates and the densities of sand soil on the settlement and moments. The following conclusions are drawn based on the reporting results:

1.When varying plate thickness for the three sand densities, the corresponding impact on the settlement can be described as following:

i) For loose sand, there is little variation in the settlement values for both plate thicknesses.

ii) For medium dense sand, there is almost no change in the settlement values for both thin and thick plates.

iii) For dense sand soil, when changing the plate thickness there is no much variation in the settlement values, similar to med dense sand soil.

2.The moment behavior of thick and thin plates rested on one of the following sand densities can be described as following:

i) For loose sand soil, the moment value for thick plate is around six times of that in thin one.

ii) For medium dense sand, the moment of thick plates was nine times of that in the thin one.

iii) For dense sand, the moment value of the thick plate is around ten times of that in the thin plate.

3.Medium dense and dense sand are both suitable to be used in the model. When the implementation cost is a concern, the med dense sand soil can be used with acceptable quality.

4.The thickness of the plate has major effect on the moment of plate resting on different types of sand. Thin plate can be a perfect choice in implementing the model to reduce the moment and the implementation costs.

\section{REFERENCES}

1. 3D-PLAXIS-Corporation (2006). Plaxis, 3D foundation Manual Version 1.5.

2. Abdul Hussein, H. 2011. Effects of flexural rigidity and soil modulus on the linear static analysis of raft foundations. Journal of Babylon University, Pure and Applied Sciences, 19.

3. AL-Hosani, K. (2001). A non-singular fundamental solution for boundary element analysis of thick plates on Winkler foundation under generalized loading. Computers \& Structures, 79, 2767-2780.

4. Al-Hosani, K. I. A. (1991). Stress analysis of thin and thick plates on elastic foundations using boundary and finite element methods.

5. Civalek, Ö. (2007). Nonlinear Analysis of Thin Rectangular Plates on WinklerPasternak Elastic Foundations by DSC-HDQ Methods. Applied Mathematical Modelling, 31, 606-624.

6. DAS, 2010 Braja M. Das, Principles of Geotechnical Engineering- Seventh Edition , Cengage Learning.

7. Huang, M.-H. and Thambiratnam, D. (2001). Analysis of plate resting on elastic supports and elastic foundation by finite strip method. Computers \& Structures, 79, 2547-2557. 
8. Marto, A., Latifi, N., Janbaz, M., Kholghifard, M., Khari, M., Alimohammadi, P., Banadaki, A. D. (2012). Foundation size Effect on modulus of subgrade Reaction on sandy soils. Electronic Journal of Geotechnical Engineering,(EJGE), 17, 2523-2530.

9. Nobakhti, S. And Aghdam, M. (2011). Static analysis of rectangular thick plates resting on two-parameter elastic boundary strips. European Journal of Mechanics-A/Solids, 30, 442-448.

10. Puttonen, J. A. V., P. 1986. Boundary element analysis of a plate on elastic foundations. Int. J. Numer. Meth. Engrg, 23, 287-303.

11. Silva, A. R., Silveira, R. A. and Goncalves, P. B. (2001). Numerical methods for analysis of plates on tensionless elastic foundations. International Journal of Solids and Structures, 38, 2083-2100.

12. Srilakshmi, G. and Rekha, B. (2011). Analysis of mat foundation using finite element method. International Journal of Earth Sciences and Engineering, 4, 113-115.

13. Straughan, W. T. (1990). Analysis of plates on elastic foundations.

14. Timoshenko, S. P. and Woinowsky-Krieger, S. 1959. Theory of plates and shells, McGraw-hill, .

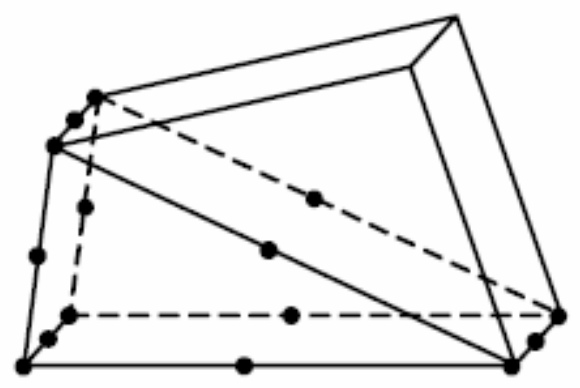

Figure (1) 15-node wedge element in 3D PLAXIS program.

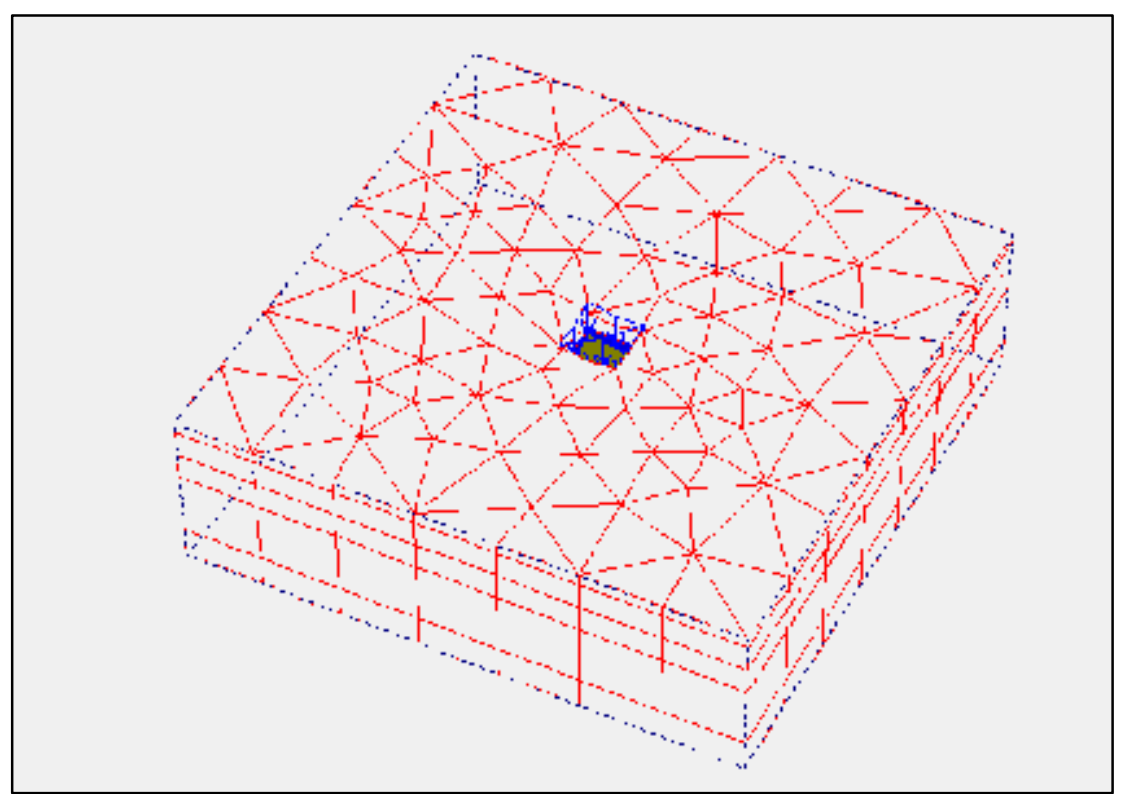

Figure (2) Three-dimensional view of the finite element mesh of plate

rested on soil 




Figure (3) Settlement of thin plate rested on loose sand soil for stress100 kN/m²

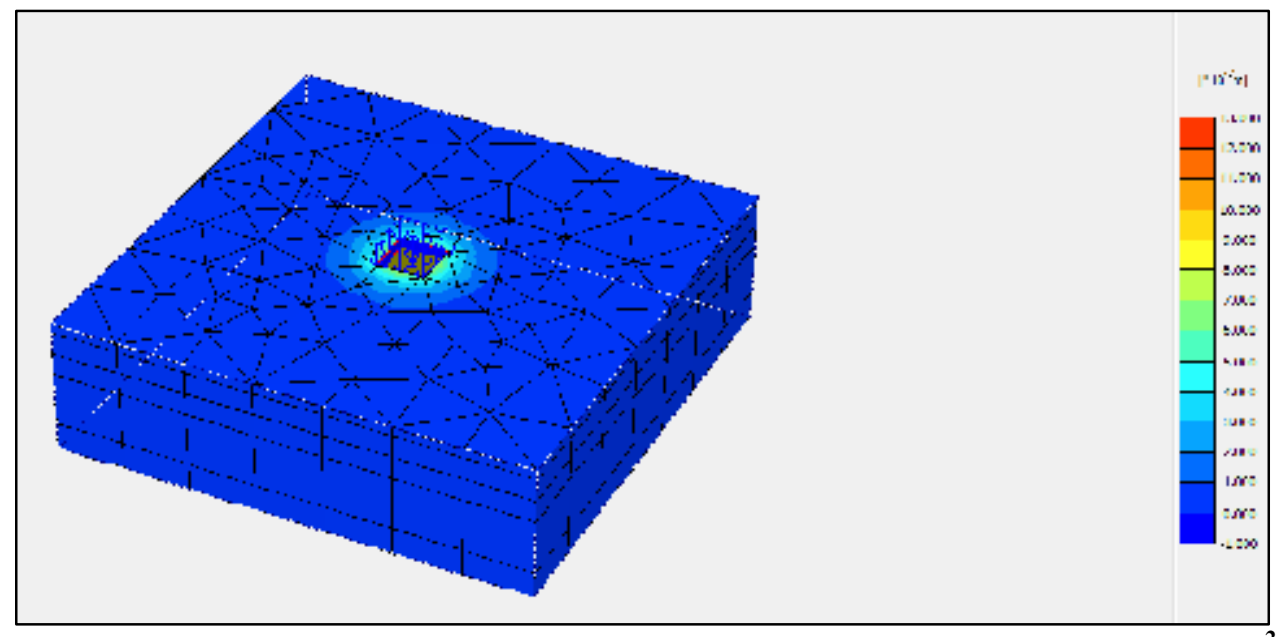

Figure (4) Settlement of thin plate rested on med dense sand soil for stress $100 \mathrm{kN} / \mathrm{m}^{2}$

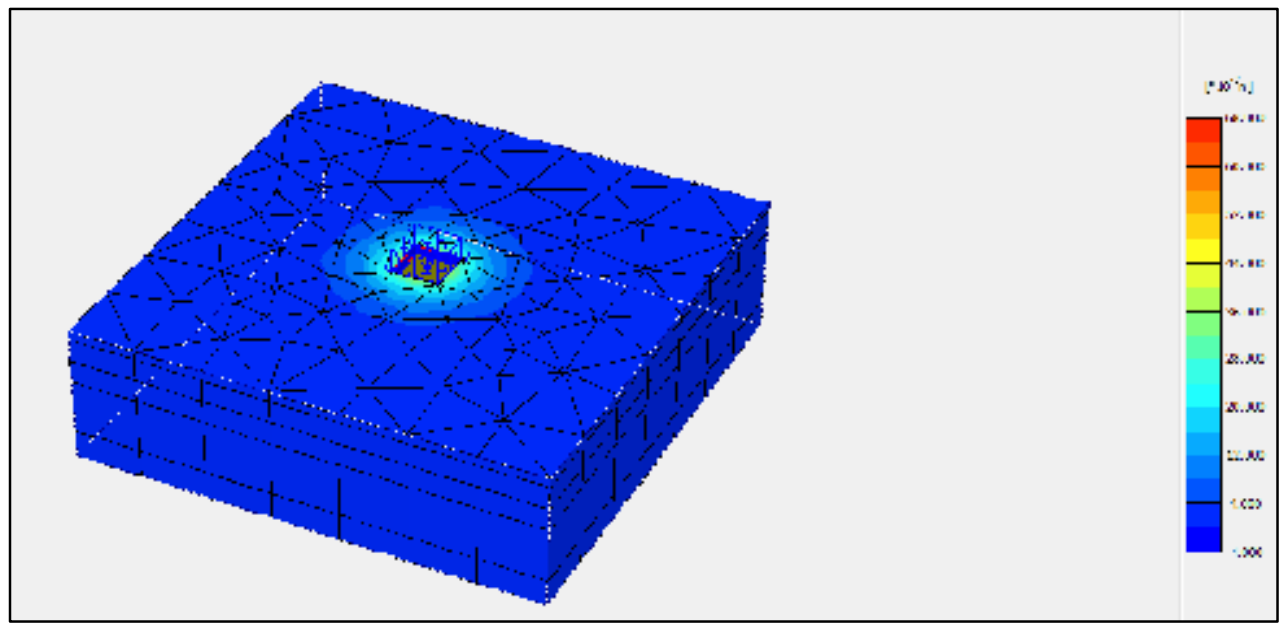

Figure (5) Settlement of thin plate rested on dense sand soil for stress $100 \mathrm{kN} / \mathrm{m}^{2}$ 


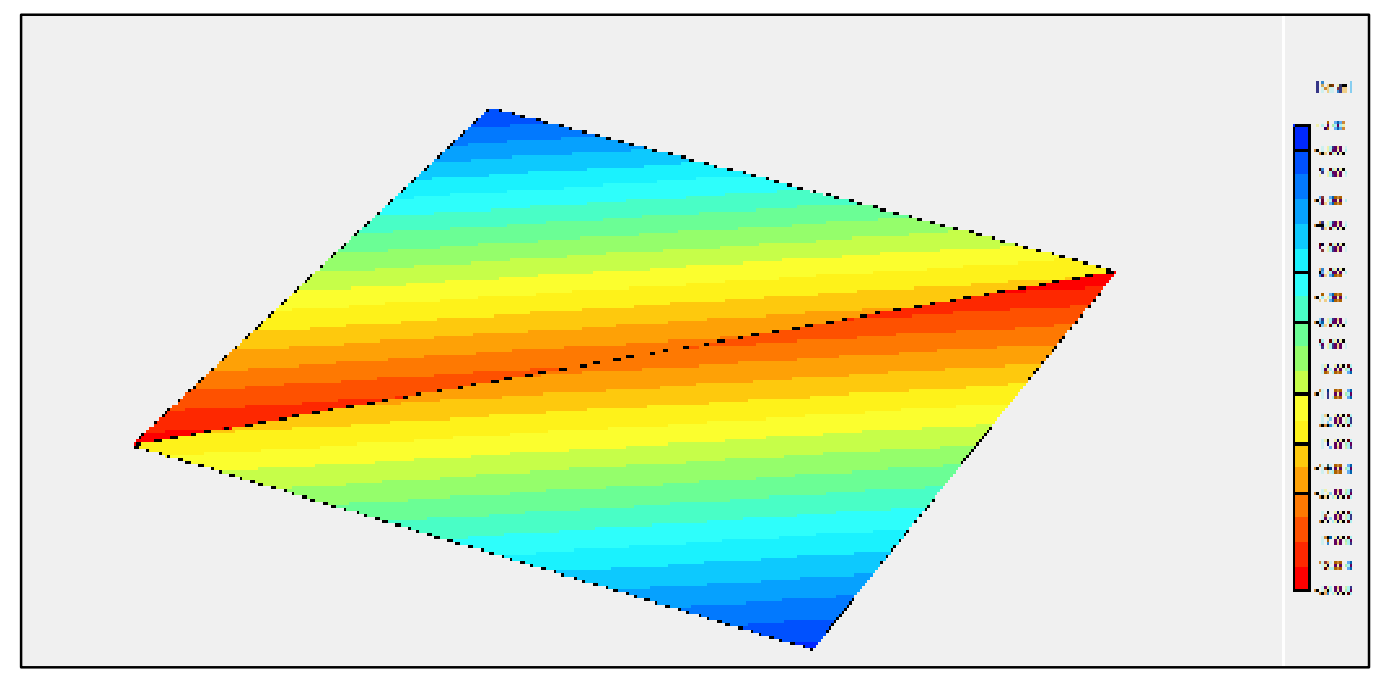

Figure (6) Moment of thin plate rested on loose sand soil for stress $100 \mathrm{kN} / \mathrm{m}^{2}$

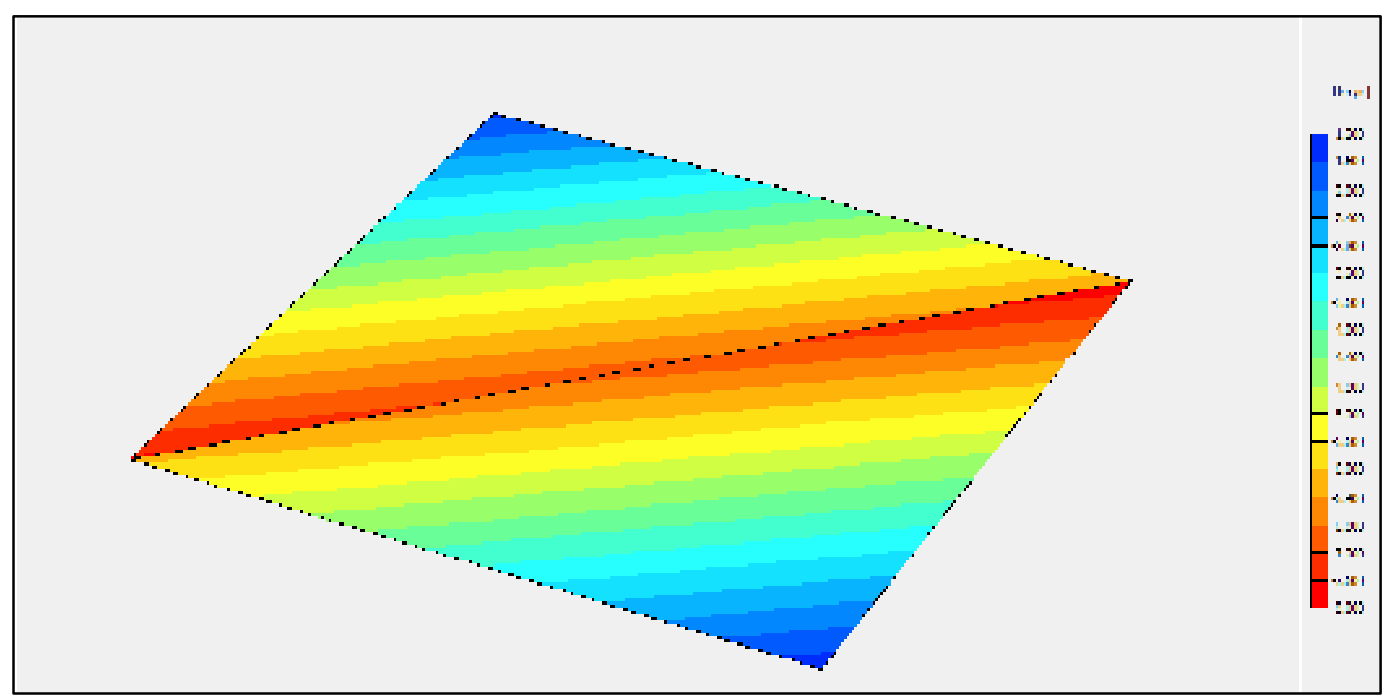

Figure (7) Moment of thin plate rested on med dense sand soil for stress $100 \mathrm{kN} / \mathrm{m}^{2}$

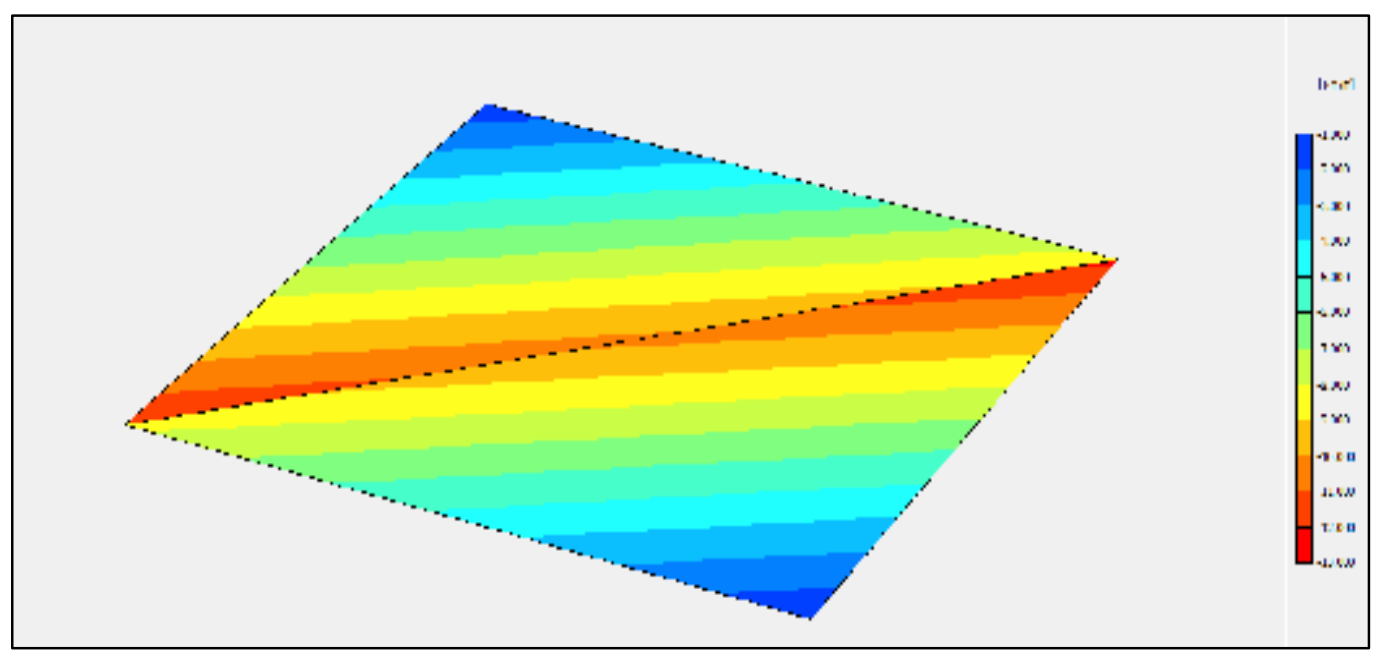

Figure (8) Moment of thin plate rested on densesand soil for stress $100 \mathrm{kN} / \mathrm{m}^{2}$ 
BEHAVIOR OF BEARING PLATES RESTING ON DIFFERENT TYPES OF SANDY SOIL



Figure (9) The relationship between the settlement and stress of thin plate for different densities

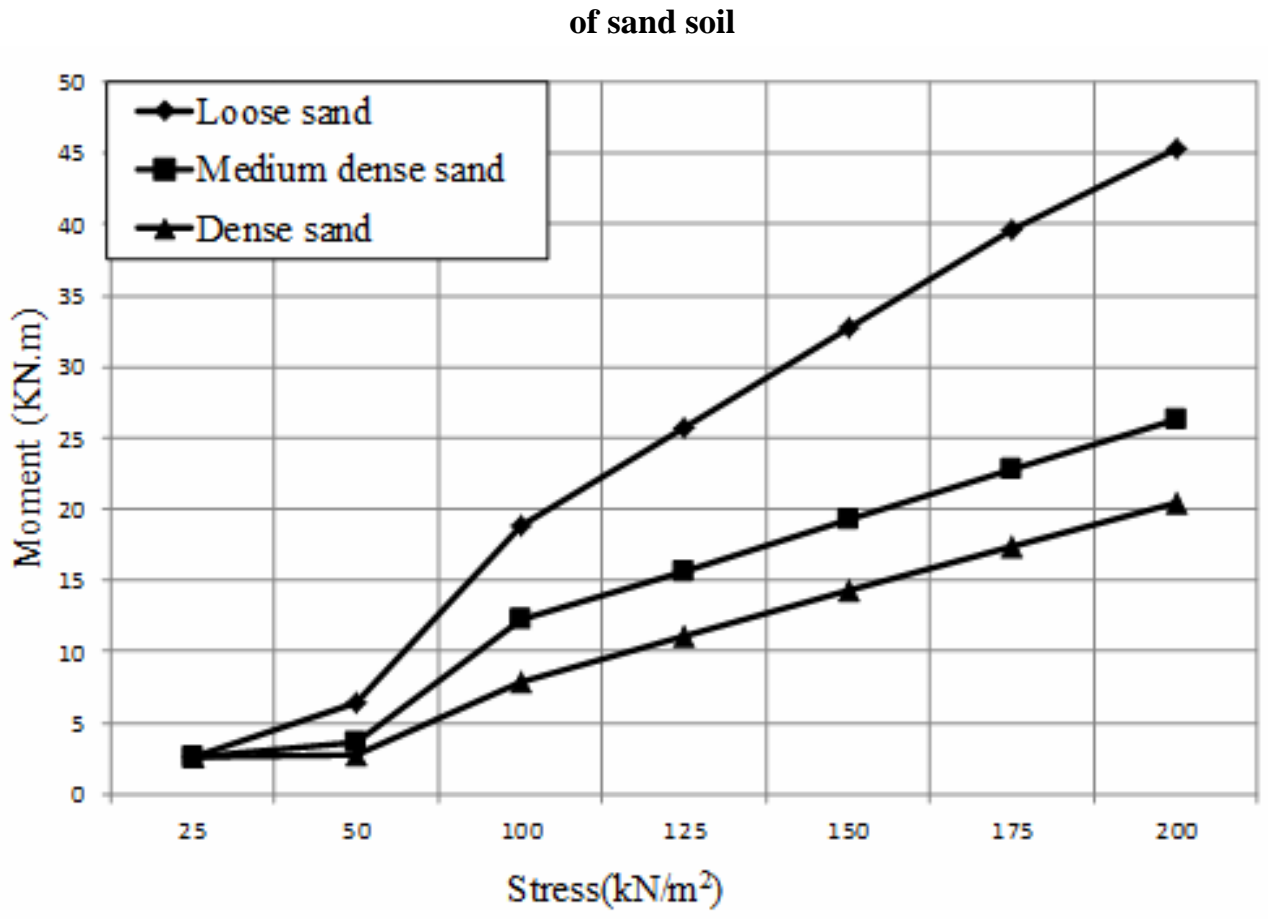

Figure (10) The relationship between the moment and stress of thin plate for different densities of sand soil 


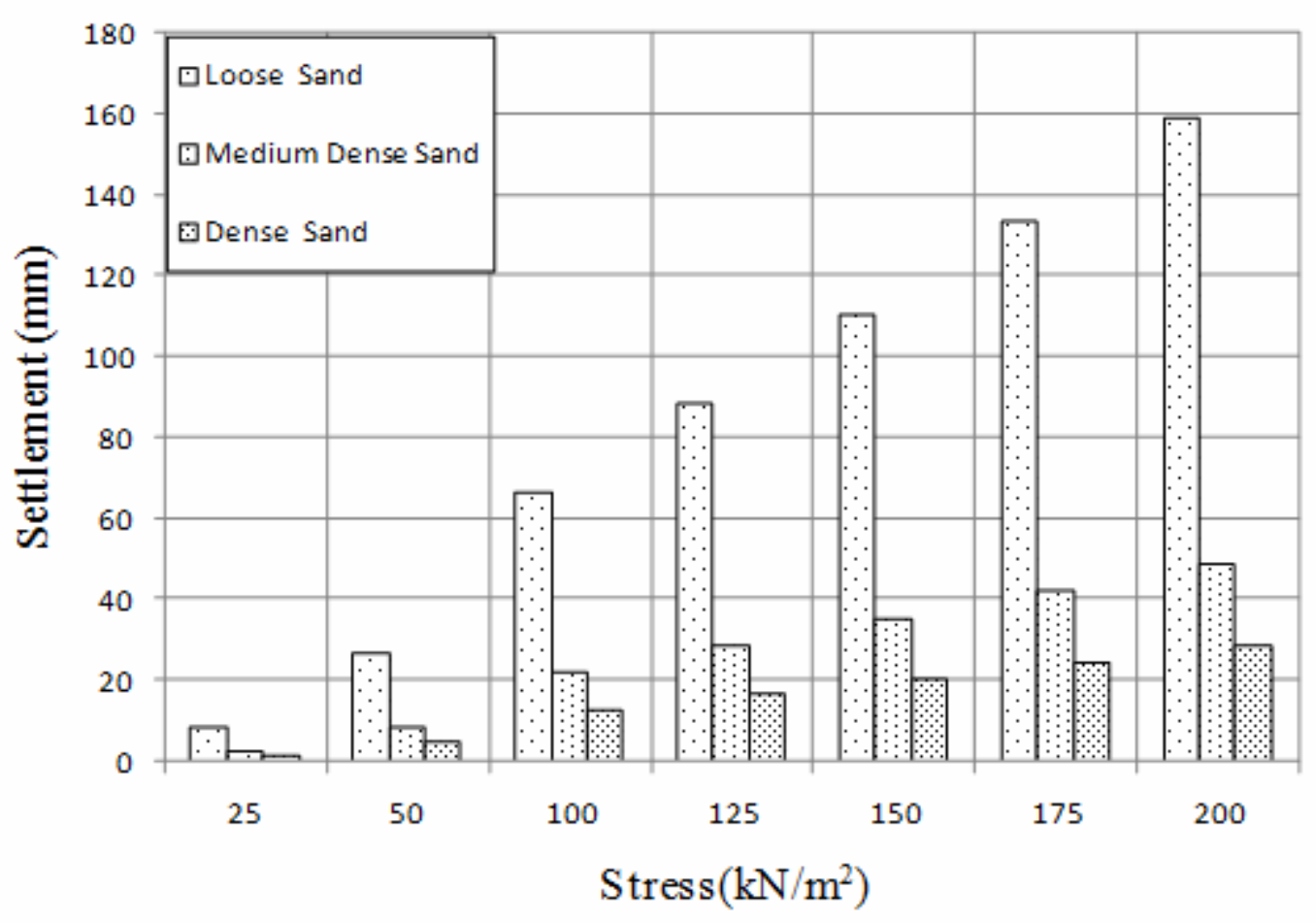

Figure (11) Comparison between settlements of thin plate rested on different densities of sand soil for different stresses

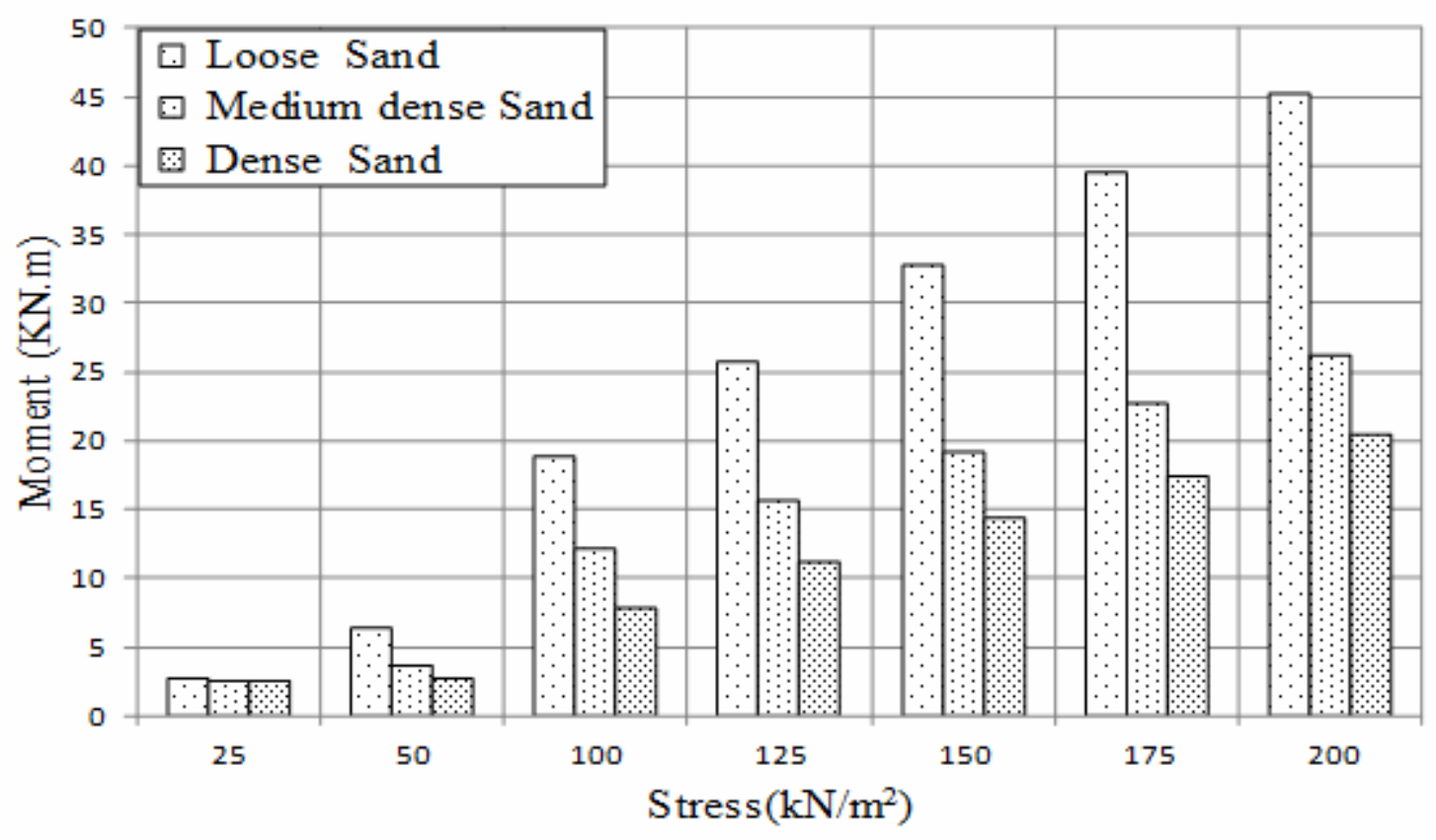

Figure (12) Comparison between moment of thin plate rested on different densities of sand for different stresses 
BEHAVIOR OF BEARING PLATES RESTING ON DIFFERENT TYPES OF SANDY SOIL

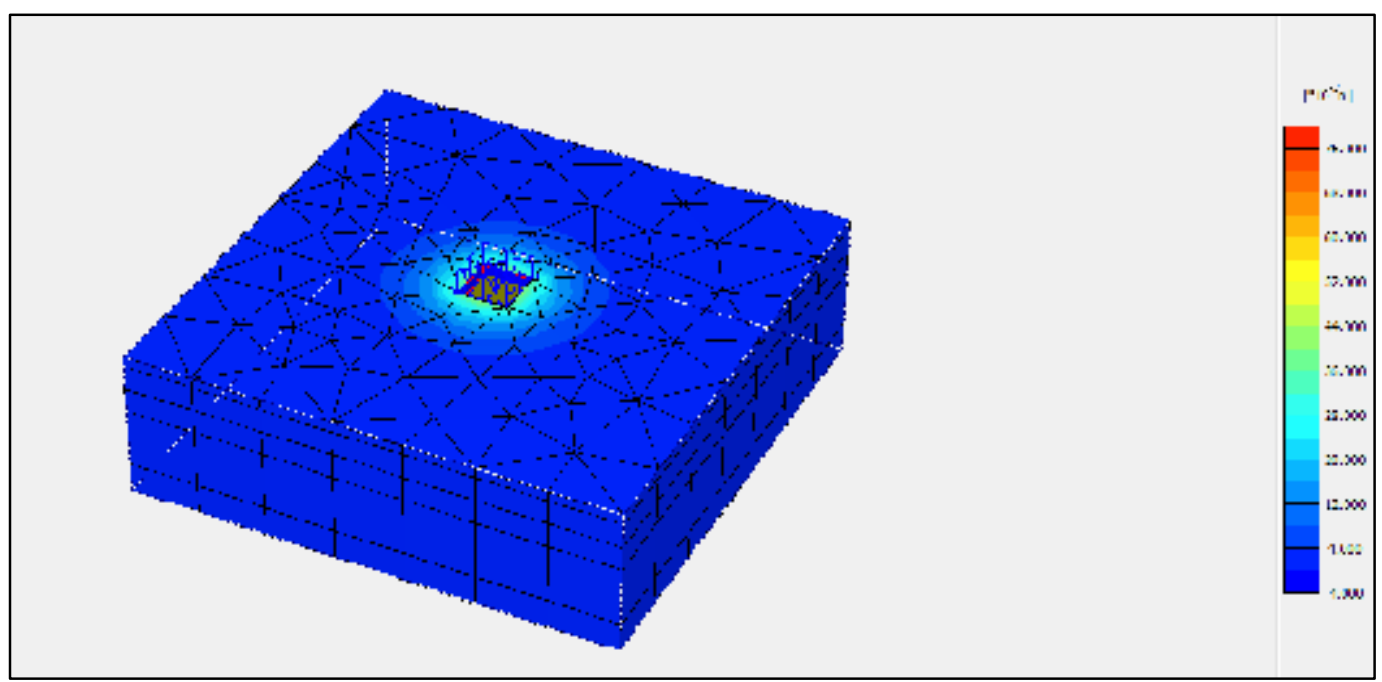

Figure (13) Settlement of thick plate rested on loose sand soil for stress $100 \mathrm{kN} / \mathrm{m}^{2}$

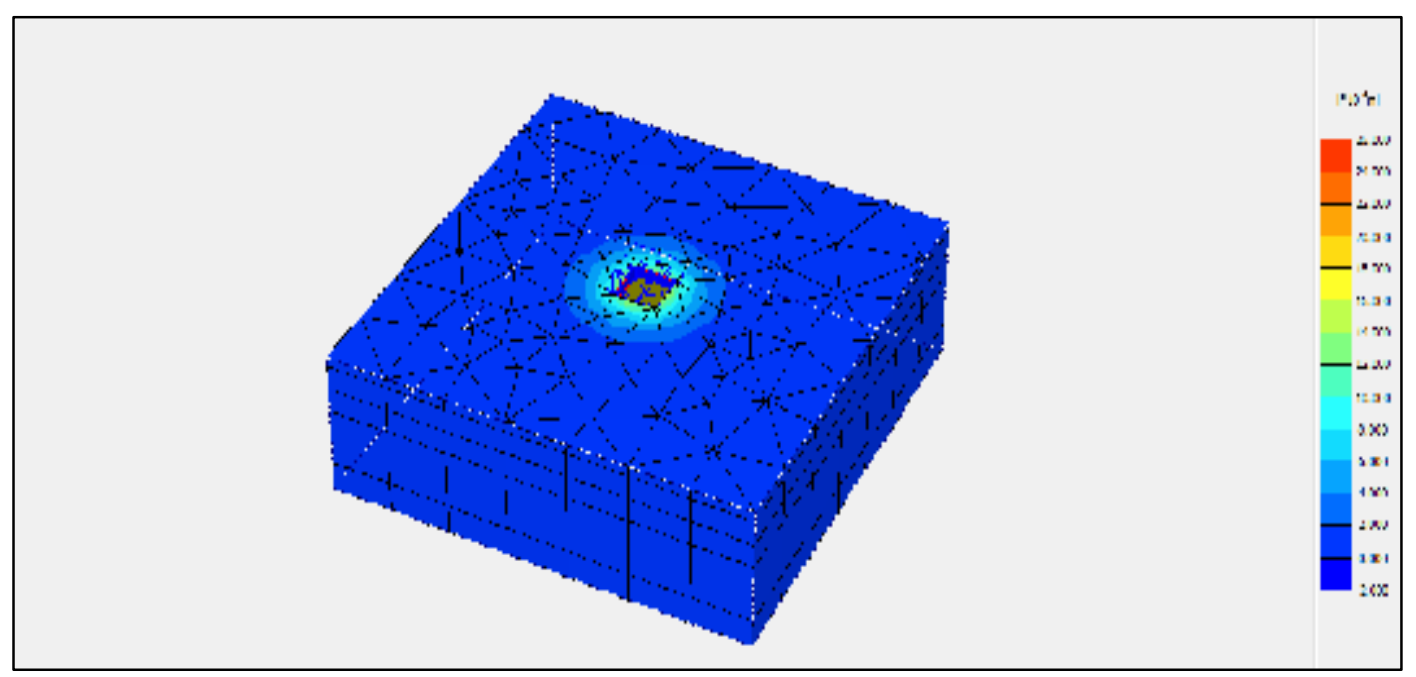

Figure (14) Settlement of thick plate rested on med dense sand soil for stress $100 \mathrm{kN} / \mathrm{m}^{2}$

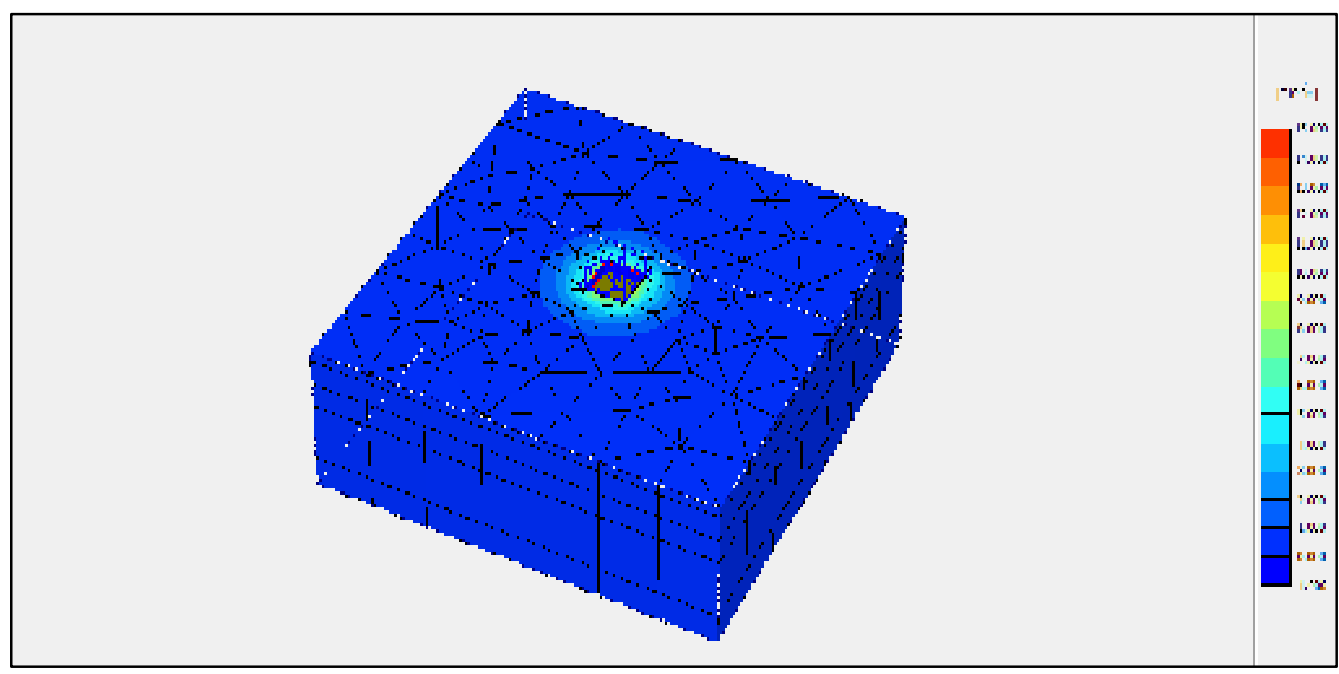

Figure (15) Settlement of thick plate rested on dense sand soil for stress $100 \mathrm{kN} / \mathrm{m}^{2}$ 


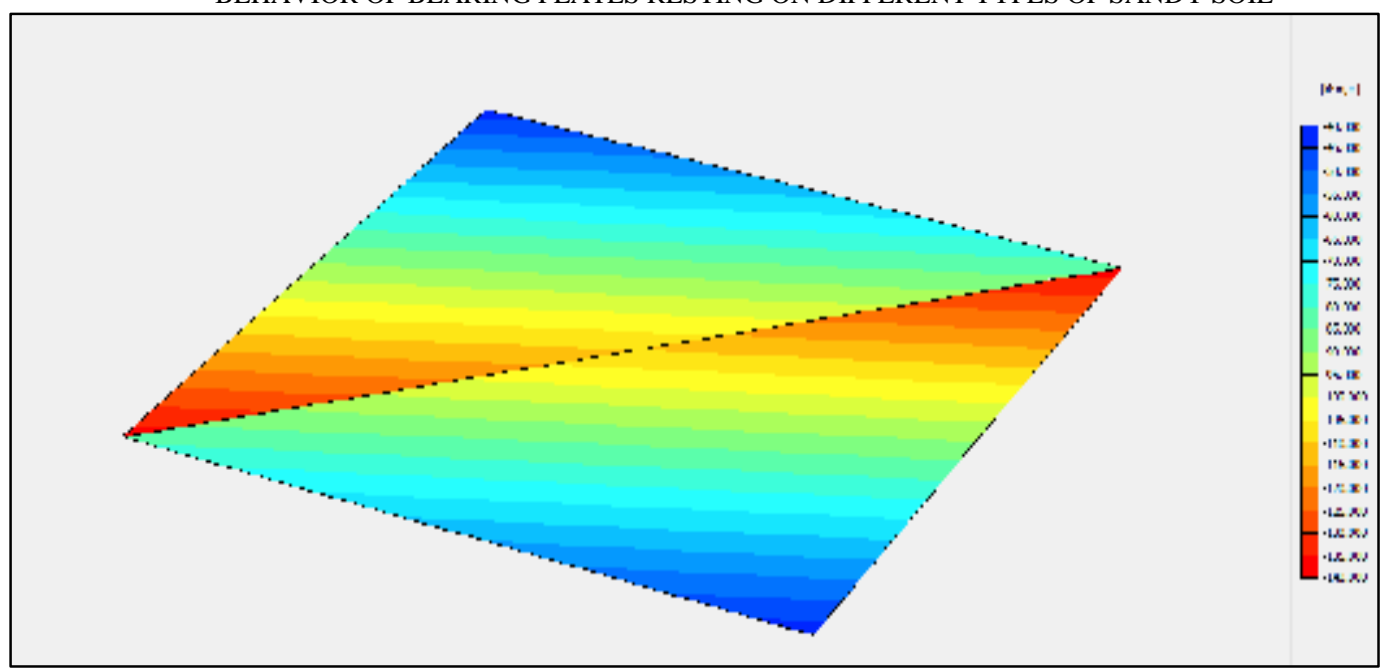

Figure (16) Moment of thick plate rested on loose sand soil for stress $100 \mathrm{kN} / \mathrm{m}^{2}$

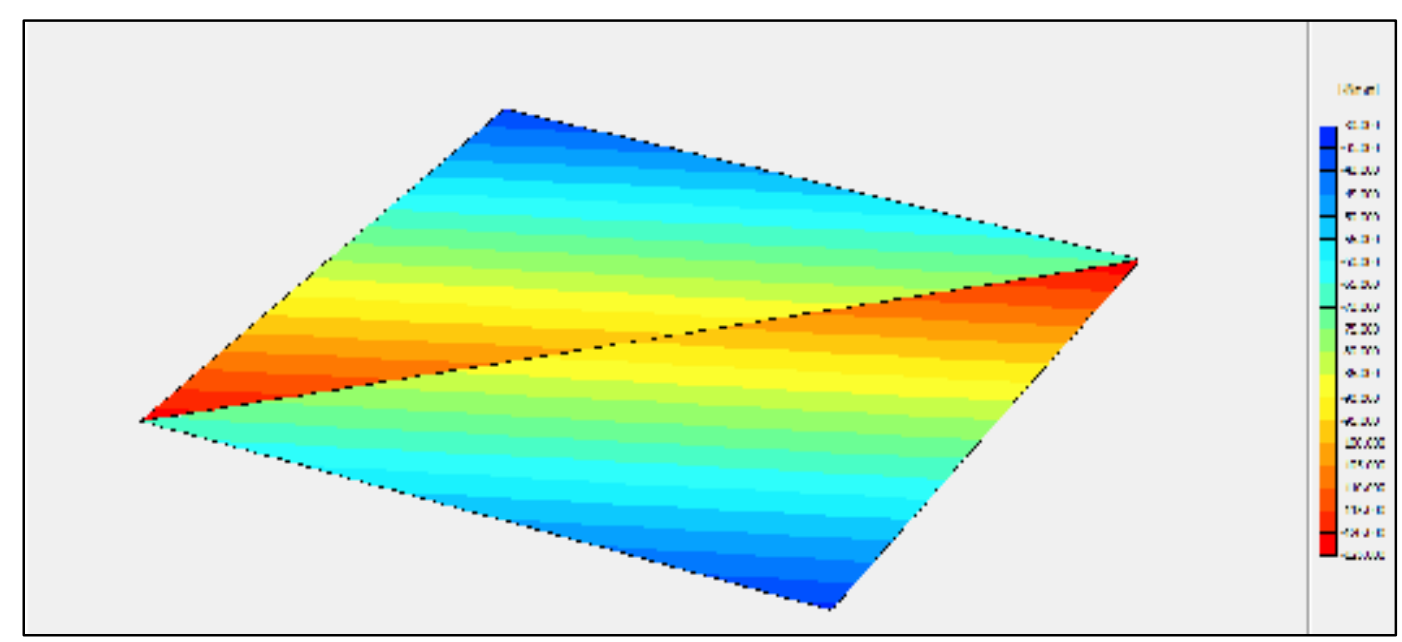

Figure (17) Moment of thick plate rested on med dense sand soil for stress $100 \mathrm{kN} / \mathrm{m}^{2}$

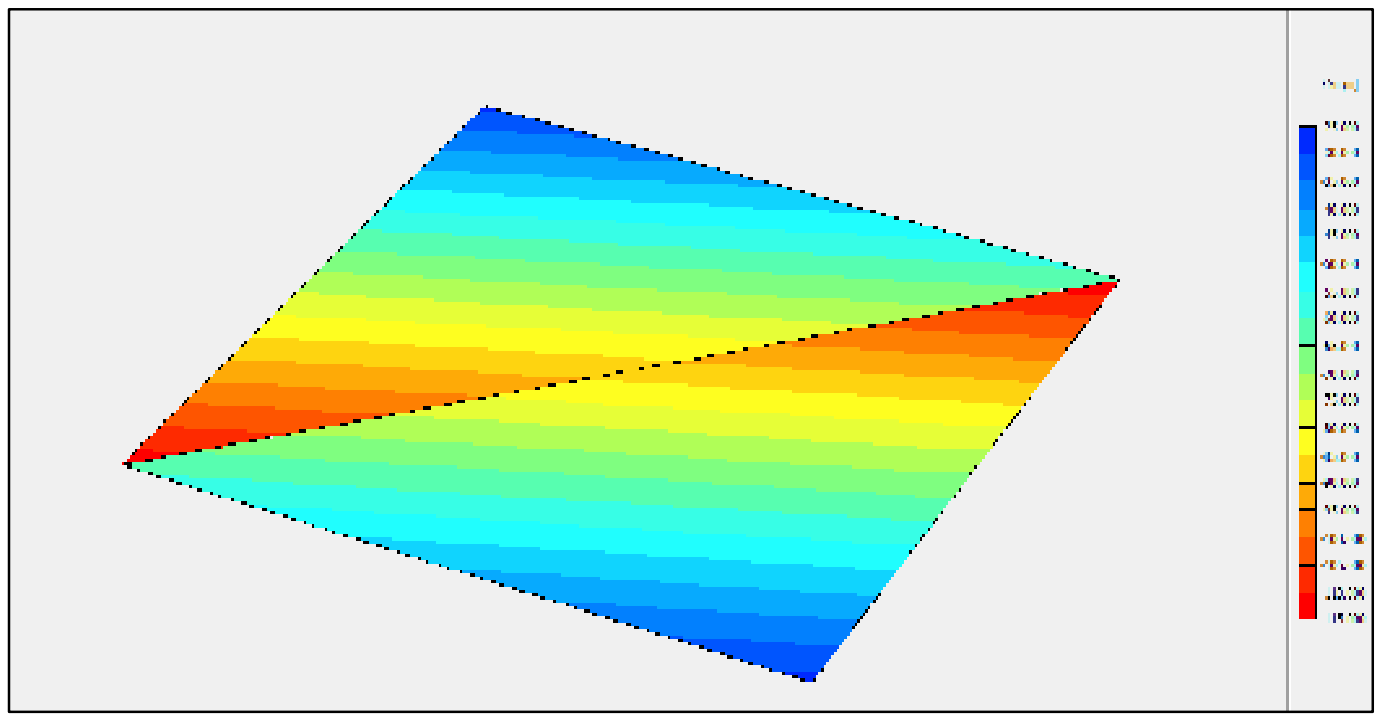

Figure (18) Moment of thick plate rested on dense sand soil for stress $100 \mathrm{kN} / \mathrm{m}^{2}$ 


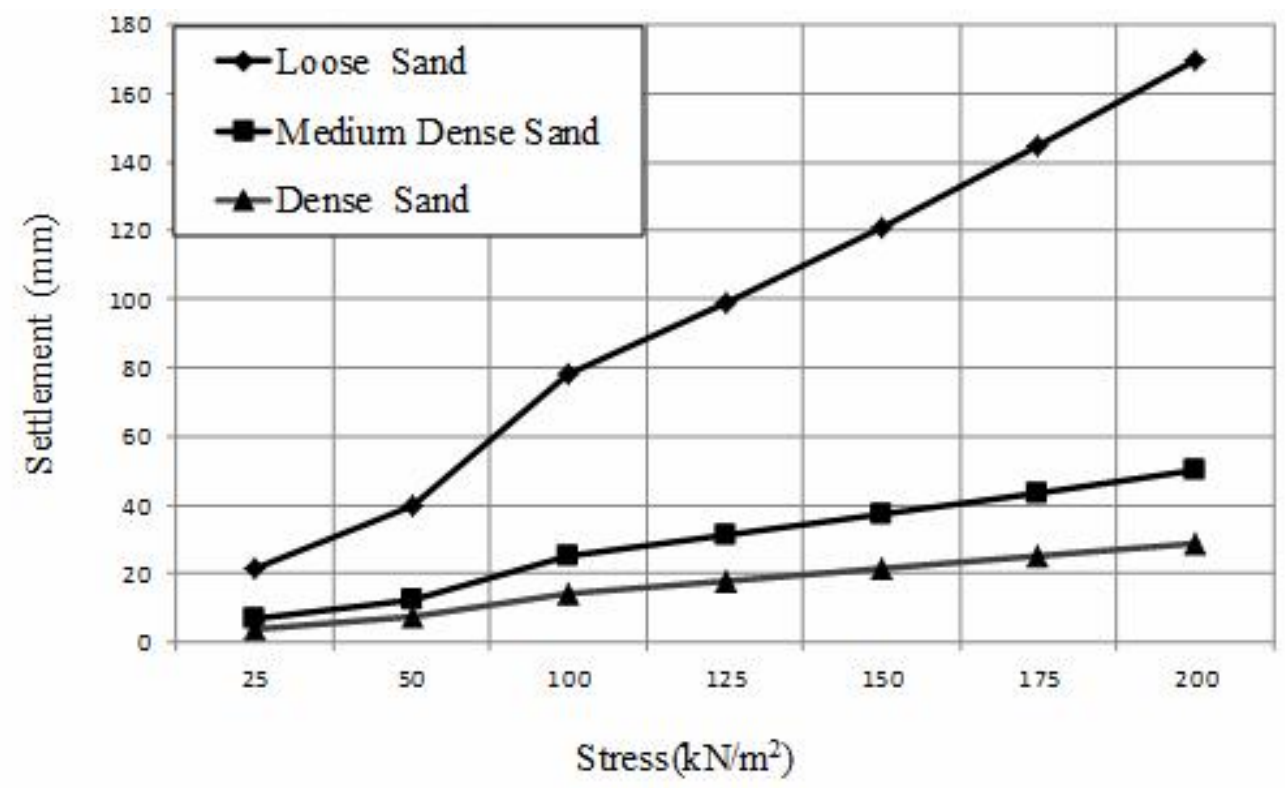

Figure (19) The relationship between the settlement and stress of thick plate for different relative densities of sand soil

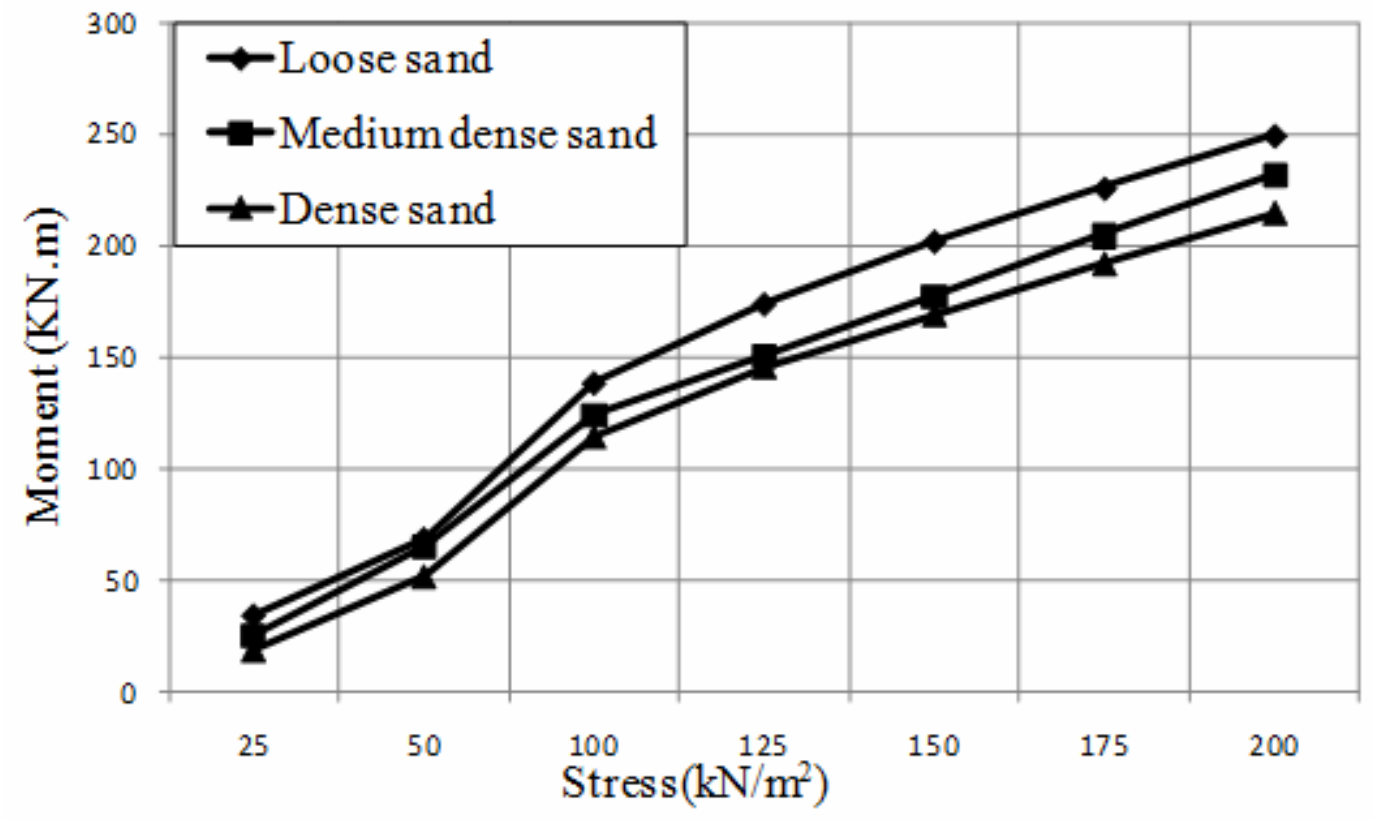

Figure (20) The relationship between the moment and stress of thick plate for different relative densities of sand soil 




Figure (21) Comparison between settlement of thick plate rested on different relative densities of sand for different stresses

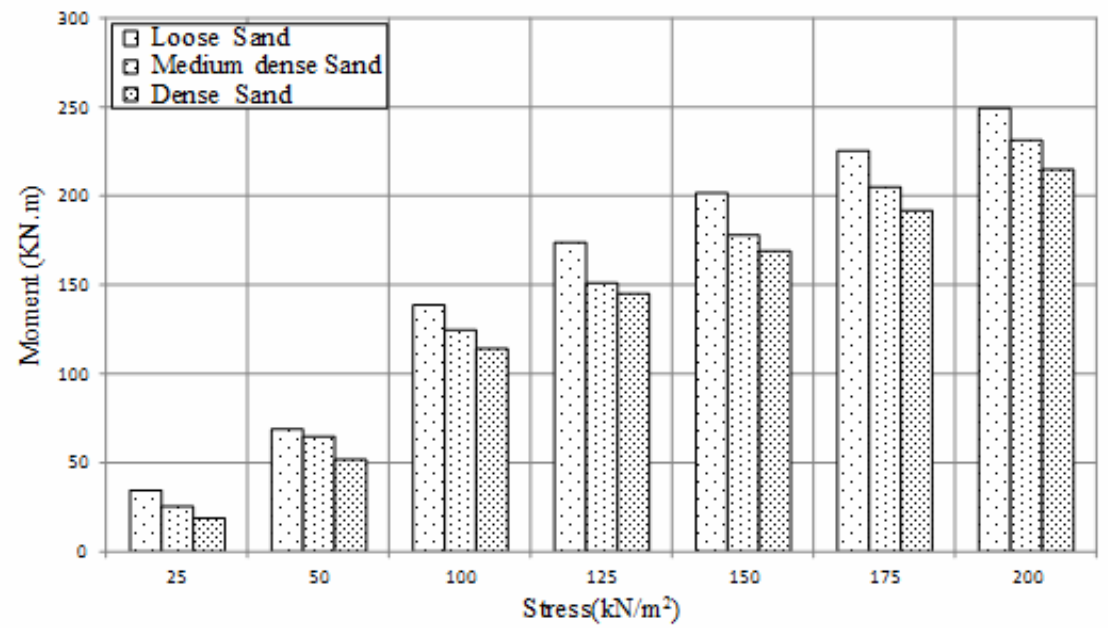

Figure (22) Comparison between moment of thick plate rested on different relative densities of sand for different stresses

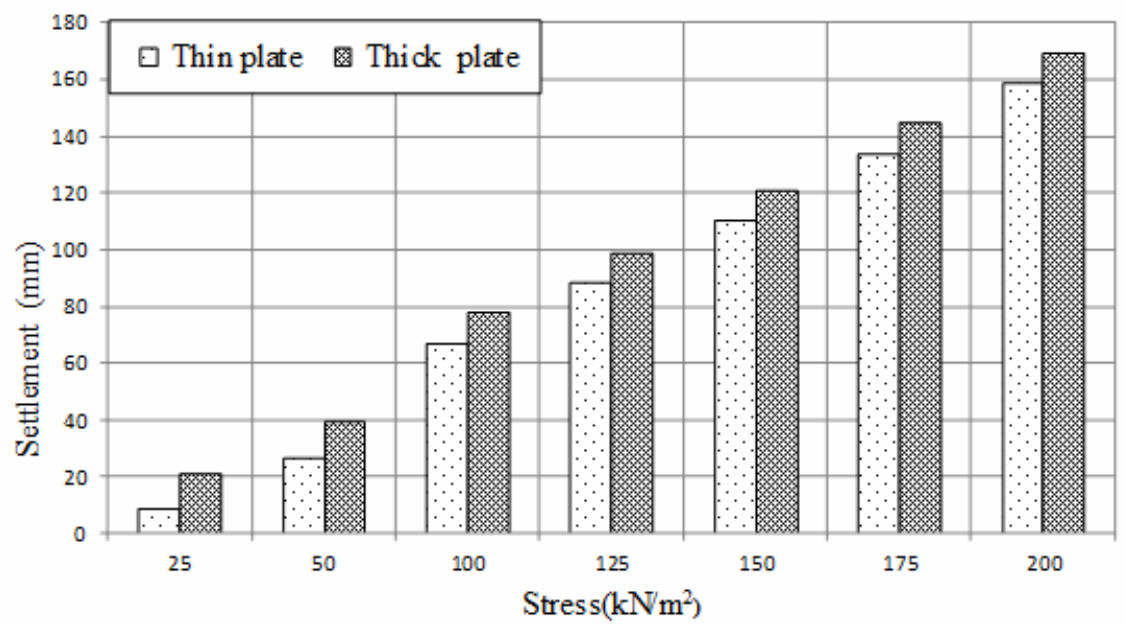

Figure (23) Comparison between settlement of thin and thick plate rested on loose sand for different stresses 
BEHAVIOR OF BEARING PLATES RESTING ON DIFFERENT TYPES OF SANDY SOIL

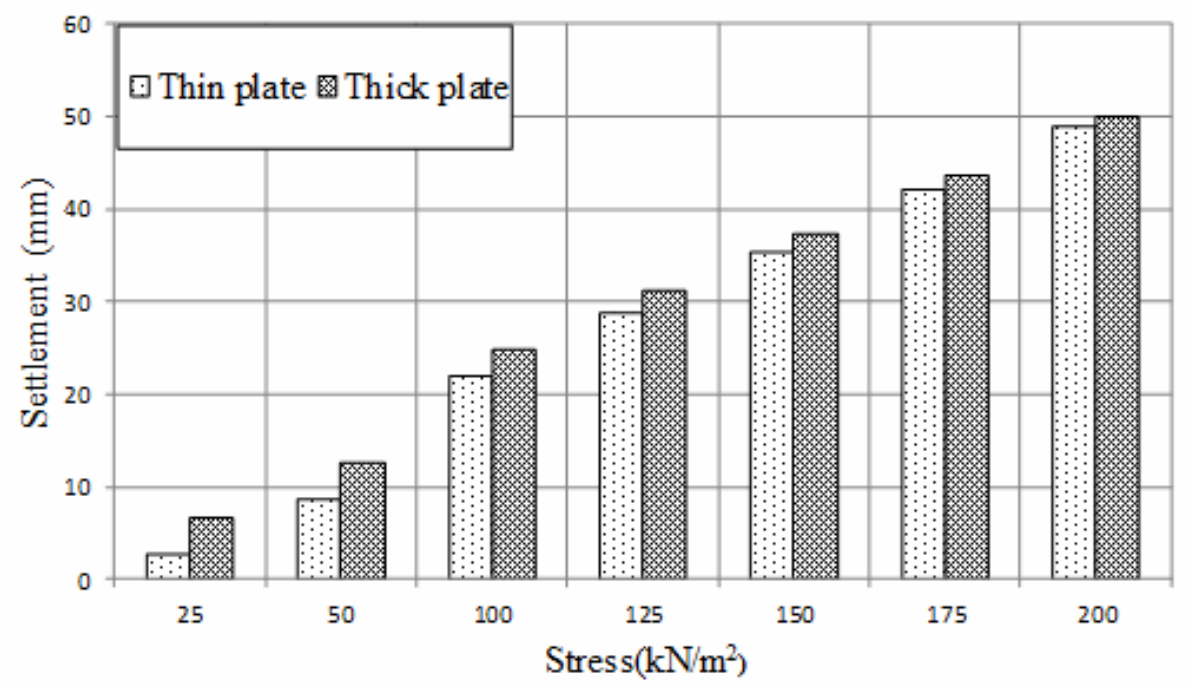

Figure (24) Comparison between settlement of thin and thick plate rested on med dense sand for different stresses

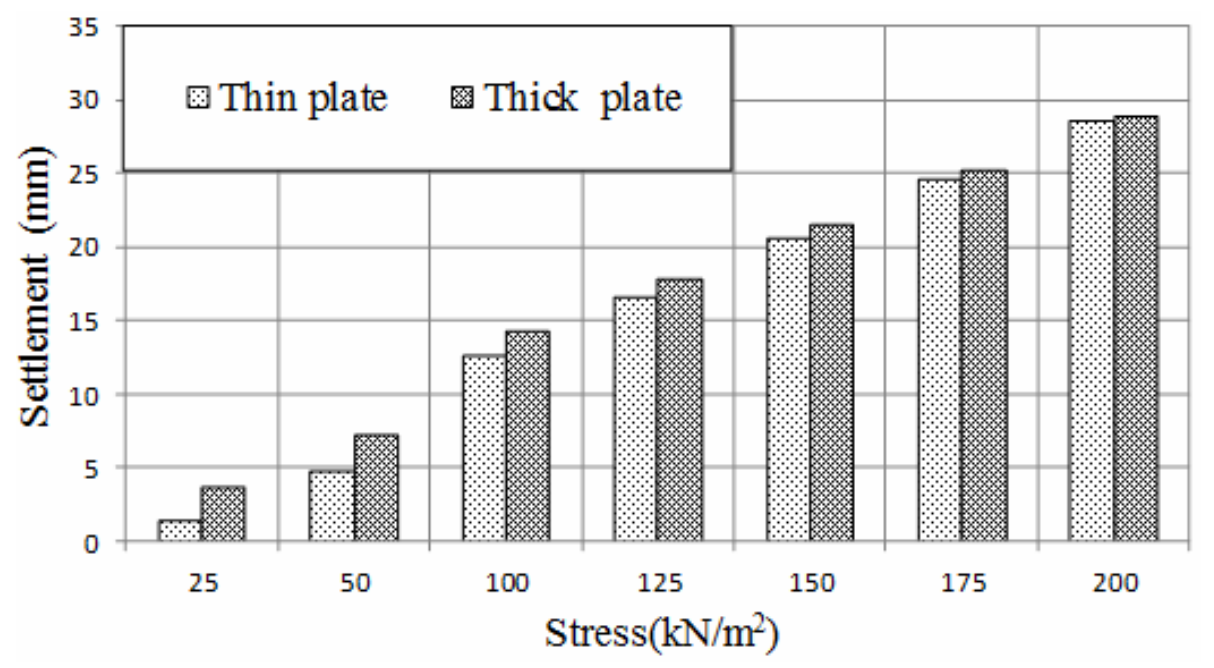

Figure (25) Comparison between settlement of thin and thick plate rested on dense sand for different stresses

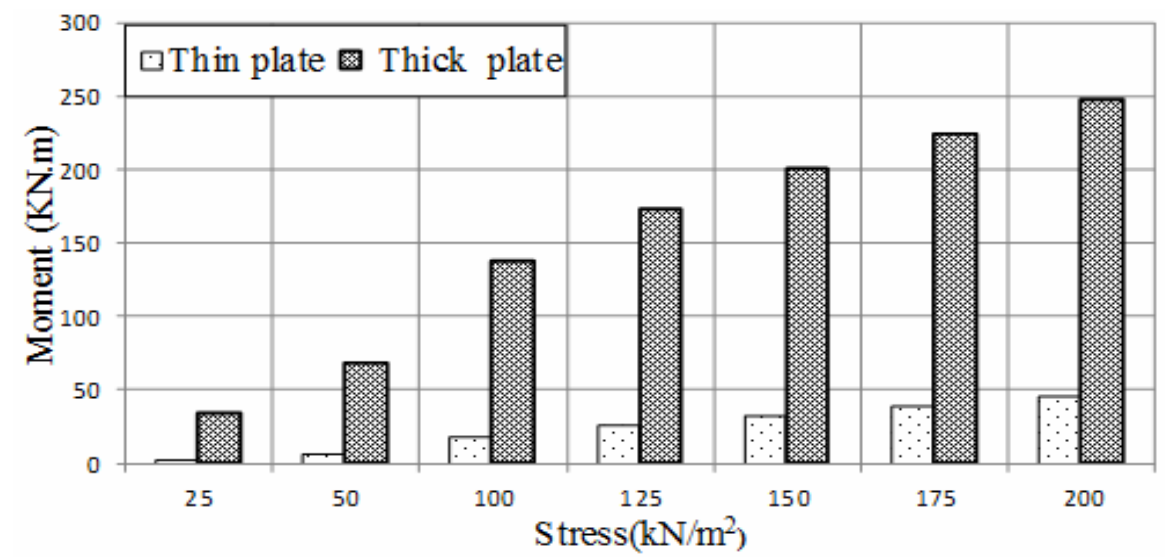

Figure (26) Comparison between moment of thin and thick plate rested on loose sand for different stresses 
BEHAVIOR OF BEARING PLATES RESTING ON DIFFERENT TYPES OF SANDY SOIL



Figure (27) Comparison between moment of thin and thick plate rested on med dense sand for different stresses

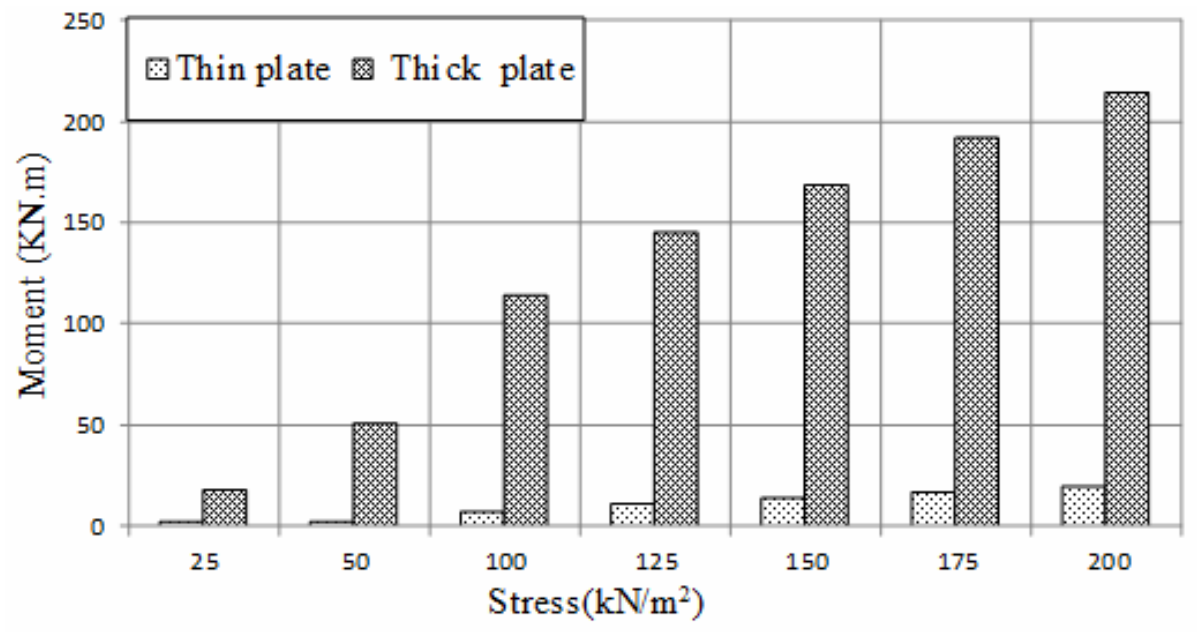

Figure (28) Comparison between moment of thin and thick plate rested on dense sand for different stresses 